Article

\title{
Genome-Wide Identification, Expression, and Functional Analysis of the Sugar Transporter Gene Family in Cassava (Manihot esculenta)
}

\author{
Qin Liu ${ }^{1,+}{ }^{+}$Huijie Dang ${ }^{1,+}$, Zhijian Chen ${ }^{2}$, Junzheng $\mathrm{Wu}^{1}{ }^{1}$, Yinhua Chen ${ }^{1}$, Songbi Chen ${ }^{2}$ and \\ Lijuan Luo ${ }^{1, *}$ \\ 1 Hainan Key Laboratory for Sustainable Utilization of Tropical Bioresources, Institute of Tropical Agriculture \\ and Forestry, Hainan University, Haikou 570110, China; 11071001110002@hainu.edu.cn (Q.L.); \\ dhj1990@hainu.edu.cn (H.D.); tang_zhijuan@hainu.edu.cn (J.W.); yhchen@hainu.edu.cn (Y.C.) \\ 2 Institute of Tropical Crop Genetic Resources, Chinese Academy of Tropical Agriculture Sciences, \\ Danzhou 571737, China; zjchen@catas.cn (Z.C.); songbichen@catas.cn (S.C.) \\ * Correspondence: 990908@hainu.edu.cn; Tel.: +86-898-6616-0722 \\ + These authors contributed equally to this work.
}

Received: 7 March 2018; Accepted: 20 March 2018; Published: 26 March 2018

\begin{abstract}
The sugar transporter (STP) gene family encodes monosaccharide transporters that contain 12 transmembrane domains and belong to the major facilitator superfamily. STP genes play critical roles in monosaccharide distribution and participate in diverse plant metabolic processes. To investigate the potential roles of STPS in cassava (Manihot esculenta) tuber root growth, genome-wide identification and expression and functional analyses of the STP gene family were performed in this study. A total of 20 MeSTP genes (MeSTP1-20) containing the Sugar_tr conserved motifs were identified from the cassava genome, which could be further classified into four distinct groups in the phylogenetic tree. The expression profiles of the MeSTP genes explored using RNA-seq data showed that most of the MeSTP genes exhibited tissue-specific expression, and 15 out of $20 \mathrm{MeSTP}$ genes were mainly expressed in the early storage root of cassava. qRT-PCR analysis further confirmed that most of the MeSTPs displayed higher expression in roots after 30 and 40 days of growth, suggesting that these genes may be involved in the early growth of tuber roots. Although all the MeSTP proteins exhibited plasma membrane localization, variations in monosaccharide transport activity were found through a complementation analysis in a yeast (Saccharomyces cerevisiae) mutant, defective in monosaccharide uptake. Among them, MeSTP2, MeSTP15, and MeSTP19 were able to efficiently complement the uptake of five monosaccharides in the yeast mutant, while MeSTP3 and MeSTP16 only grew on medium containing galactose, suggesting that these two MeSTP proteins are transporters specific for galactose. This study provides significant insights into the potential functions of MeSTPs in early tuber root growth, which possibly involves the regulation of monosaccharide distribution.
\end{abstract}

Keywords: cassava; sugar transporter; gene family; sugar unloading; tuber root

\section{Introduction}

Sugar, regarded as an essential substrate in carbon and energy metabolism, plays diverse roles in plant growth and development. Sugars also act as signal molecules for signal transduction and as important elements for the synthesis of cellular compounds, contributing to the regulation of osmotic homeostasis [1]. In plants, sugars are transported from source tissues (e.g., leaves) to sink tissues (such as roots, seeds, and other reproductive tissues) mainly in the form of sucrose, polyols, or oligosaccharides. As the major carbohydrate in plants, sucrose is mainly synthesized in the 
mesophyll. After allocation to the collection phloem, sucrose is translocated via a long-distance transport system in the transport phloem and finally transported to the release phloem. A variety of strategies have been evolved by plants for the release of sucrose from the phloem to the sink tissues. For example, at the release phloem, sucrose can be transported to sink cells via a symplastic pathway through plasmodesmata or via an apoplastic pathway mediated by sucrose transporters, cell wall invertases, and monosaccharide transporters [2]. The uptake of hexose (e.g., glucose and fructose) hydrolyzed from sucrose in the apoplast is regulated by a group of transporters, such as sugar transporter proteins (STPs) in Arabidopsis, monosaccharide transporters (MSTs) in rice (Oryza sativa), and hexose transporters (HTs) in grape (Vitis vinifera), which are involved in sugar unloading and thus contribute to carbon partitioning, crop yield, and environmental adaptation [3].

STP proteins belong to the major facilitator superfamily commonly possessing 12 transmembrane domains and are regarded as $\mathrm{H}^{+}$/sugar symporters [4]. Since the first STP gene was cloned from Chlorella [5], a set of STP genes have been identified and characterized from other plant species, such as Arabidopsis, rice, grape, tomato (Lycopersicon esculentum), and pear (Pyrus bretschneideri) [6-11]. Most of the characterized STP proteins are plasma membrane-localized transporters and exhibit acquisition of broad monosaccharide substrates, such as glucose, fructose, galactose, xylose, and mannose [6]. Cumulative results demonstrate that STP genes display different expression patterns during plant growth and respond to stress conditions. In Arabidopsis, for example, AtSTP1 is mainly expressed in germinating seeds, young seedlings, and guard cells [12]. AtSTP2, AtSTP6, AtSTP9, and AtSTP11 show tissue-specific expression in pollen, while AtSTP4 exhibits the highest expression in roots [6,13]. AtSTP13, localized to the vasculature and leaf mesophyll cells, probably participates in the retrieval of sugars leaked from the cytoplasm [14]. In rice, OsMST3 is expressed specifically in the root xylem involved in the accumulation of monosaccharides required for cell wall synthesis at the stage of cell thickening [7]. Furthermore, STP genes also respond to environmental stresses, such as wounding [13,15], nematode infection [16], and pathogen attack [17]. Although the expression patterns and functional analysis of STP genes have been previously studied, the comprehensive expression profiles of the STP gene family in root crops, such as cassava (Manihot esculenta), are poorly characterized and may provide significant insights into the various roles of STPS in different plant species.

Cassava is the third largest source of food cultivated in tropical and subtropical areas, providing food for more than 800 million people globally [18]. As its high starch content accumulates in tuber roots, cassava is a major source for the industrial production of starch and bioethanol $[19,20]$. In the past two decades, numerous in silico data were generated and used for the screening of potential genes of particular traits in cassava, including those involved in cyanogenic glucoside synthesis [21], post-harvest physiological deterioration [22], storage roots development [23], biotic and abiotic stress responses [24,25]. All those data, along with the cassava genome, guarantee the possibility to analyze gene structure, chromosome location, phylogeny, evolutionary patterns, and expression profiles of gene families at a genome-wide level, as exemplified by the studies of MeFRK, MeHXK, MeWRKY, and MeMAPK families [26-29]. However, little information on STP gene family expression in different tissues and developmental roots of cassava is available. Because of the vital functions of STPS in plants, it is of considerable importance to investigate the STP gene family in cassava. In this study, the MeSTP gene family was identified from cassava genome, and a in silico analysis of MeSTP genes was conducted in detail. The expression profiles of MeSTP genes in different tissues and in the developmental roots of cassava were explored using the publicly available transcriptome data. The expression of STP genes in the roots was then confirmed by quantitative RT-PCR (qRT-PCR) analysis. Furthermore, functional and subcellular localization analyses of MeSTPs were performed. 


\section{Results}

\subsection{Identification of the STP Gene Family in Cassava}

In this study, a total of 20 putative MeSTP genes were identified in the cassava genome through a BLAST search and HMMER analysis. General information for the $20 \mathrm{MeSTP}$ members is summarized in Table 1. The 20 MeSTP genes were unevenly located on cassava chromosomes and thus they were named MeSTP1 to MeSTP20, according to their chromosomal positions (Table 1). Among them, chromosome 1, 3, and 15 had three MeSTPs each, chromosomes 2, 6, and 16 contained two MeSTPs each, and chromosomes 4, 11, 14, 17, and 18 contained one MeSTP each (Table 1). The open reading frames (ORFs) of the MeSTP genes ranged from 1326 to $1593 \mathrm{bp}$ in length (Table 1). The length of the MeSTP proteins ranged from 442 to 531 amino acids, with predicted molecular weights from $48.74 \mathrm{kDa}$ to $58.54 \mathrm{kDa}$. The theoretical isoelectric point $(\mathrm{p} I)$ of the MeSTP proteins ranged from 6.84 to 10.06. Furthermore, 19 of the 20 MeSTPs harbored 10 to 12 conserved transmembrane domains (TMDs), while MeSTP18 carried only 8 TMDs (Table 1 ).

Table 1. Information about the STP genes in cassava.

\begin{tabular}{ccccccc}
\hline Gene Name & Gene Locus & CDS Length (bp) & AA $^{\mathbf{a}}$ & $\mathbf{M W}^{\mathbf{b}} \mathbf{( k D a )}$ & $\mathbf{p I}^{\mathbf{c}}$ & $\mathbf{T M D}^{\mathbf{d}}$ \\
\hline MeSTP1 & Manes.01G067100 & 1560 & 519 & 57.08 & 8.51 & 11 \\
MeSTP2 & Manes.01G164600 & 1566 & 521 & 57.48 & 10.06 & 12 \\
MeSTP3 & Manes.01G182200 & 1392 & 463 & 51.28 & 9.4 & 10 \\
MeSTP4 & Manes.02G122000 & 1575 & 524 & 57.37 & 9.91 & 12 \\
MeSTP5 & Manes.02G122100 & 1536 & 511 & 56.51 & 9.08 & 11 \\
MeSTP6 & Manes.03G025000 & 1530 & 509 & 55.91 & 8.81 & 10 \\
MeSTP7 & Manes.03G180400 & 1590 & 529 & 58.25 & 9.26 & 12 \\
MeSTP8 & Manes.03G180600 & 1482 & 493 & 54.36 & 9.02 & 11 \\
MeSTP9 & Manes.04G053100 & 1545 & 514 & 56.31 & 7.44 & 12 \\
MeSTP10 & Manes.06G132600 & 1524 & 507 & 55.70 & 9.34 & 10 \\
MeSTP11 & Manes.06G132700 & 1527 & 508 & 55.37 & 9.61 & 10 \\
MeSTP12 & Manes.11G102900 & 1545 & 514 & 56.07 & 8.85 & 12 \\
MeSTP13 & Manes.14G139800 & 1548 & 515 & 55.51 & 9.08 & 11 \\
MeSTP14 & Manes.15G027100 & 1548 & 515 & 56.84 & 6.84 & 12 \\
MeSTP15 & Manes.15G027300 & 1596 & 531 & 58.54 & 8.85 & 12 \\
MeSTP16 & Manes.15G030700 & 1548 & 515 & 56.21 & 8.97 & 12 \\
MeSTP17 & Manes.16G020100 & 1575 & 524 & 57.85 & 9.16 & 12 \\
MeSTP18 & Manes.16G111500 & 1329 & 442 & 48.97 & 9.94 & 8 \\
MeSTP19 & Manes.17G033300 & 1569 & 522 & 57.58 & 8.9 & 12 \\
MeSTP20 & Manes.18G067900 & 1347 & 448 & 48.74 & 10.09 & 11 \\
\hline
\end{tabular}

${ }^{a}$ Length of the amino acid sequence; ${ }^{b}$ Molecular weight of the amino acid sequence; ${ }^{c}$ Isoelectric point of the MeSTP; ${ }^{d}$ Number of transmembrane domains, as predicted by the TMHMM Server v2.0.

\subsection{Sequence Structure Features of MeSTPs}

The results showed that the 20 MeSTP genes could be classified into three distinct groups according to the similarity of their gene sequences (Figure 1). The largest group contained 12 MeSTP genes, while the other two groups contained 5 and 3 MeSTP genes, respectively (Figure 1). The structure of the MeSTP genes commonly presented four exons divided by three introns, except for MeSTP7, MeSTP8, MeSTP10, MeSTP11, MeSTP15, and MeSTP20 (Figure 1). Of these, MeSTP8 together with MeSTP10, MeSTP11, and MeSTP20 possessed three exons and two introns. MeSTP7 and MeSTP15 contained five exons divided by four introns, while MeSTP18 had six exons and five introns (Figure 1). Furthermore, most of the MeSTP genes classified into the same subgroup exhibited similar gene structures, except for MeSTP6 and MeSTP18, which possessed four exons and six exons, respectively (Figure 1). 

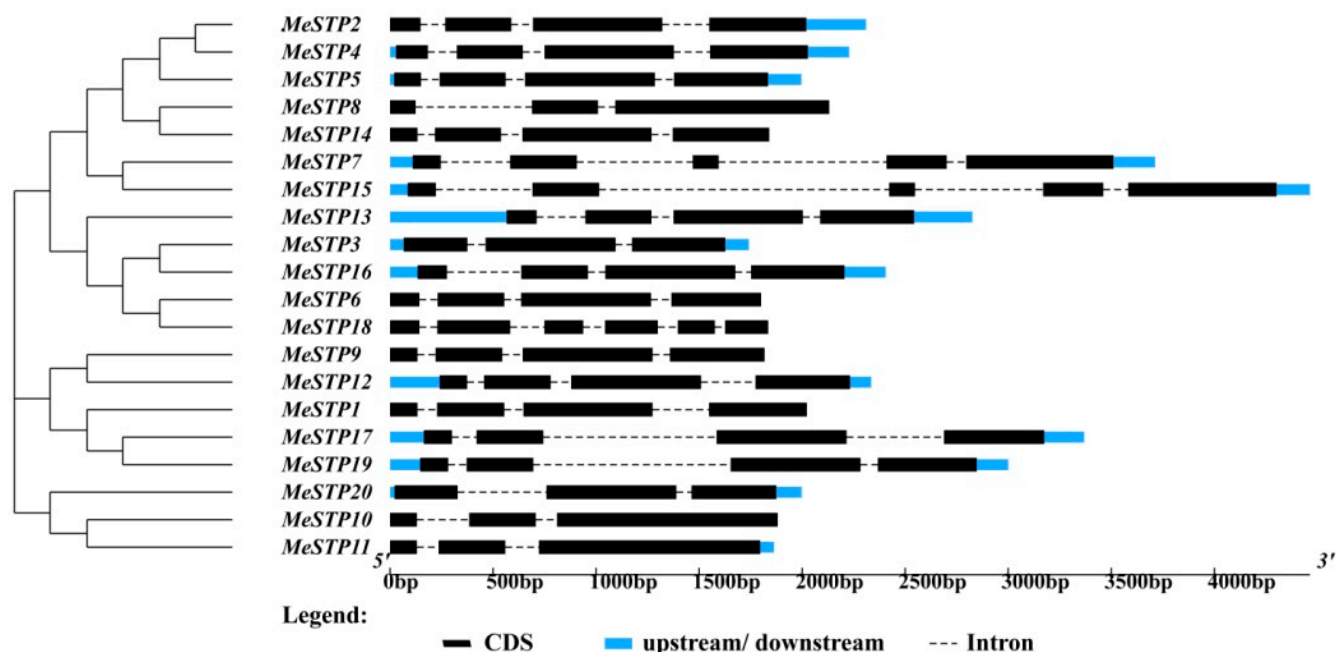

Figure 1. Exon-intron structures of the 20 MeSTP genes generated from the GSDS website (http: //gsds.cbi.pku.edu.cn/chinese.php). The neighbor-joining phylogenetic tree of the MeSTPs gene sequences was constructed using 1000 bootstrap replicates by MEGA v7.0 (Pennsylvania State University, Philadelphia, PA, USA).

Conserved motifs of the MeSTP proteins were identified using the MEME program, and the motif sequences and annotations were further predicted by Pfam. The results showed that 12 putative conserved motifs were identified in most of the MeSTP proteins (Table 2 and Figure 2). The length of the conserved motifs ranged from 15 to 82 amino acids, and putative Sugar_tr domains were predicted in conserved motifs 1 through 7 of the MeSTP proteins (Table 2). Furthermore, motifs 1, 2, 3, 4, 6, and 7 , harboring Sugar_tr domains, exhibited high conservation in the twenty MeSTP proteins (Figure 2). It was found that all of the MeSTP proteins contain the 12 motifs, except for MeSTP3, MeSTP18, and MeSTP20. For example, MeSTP3 misses motif 12 in the N-terminal region, and MeSTP20 lacks motif 9 in the C-terminal region. MeSTP18 lacks motifs 5, 8, 10, 11, and 12 in the middle of the protein sequence (Figure 2).

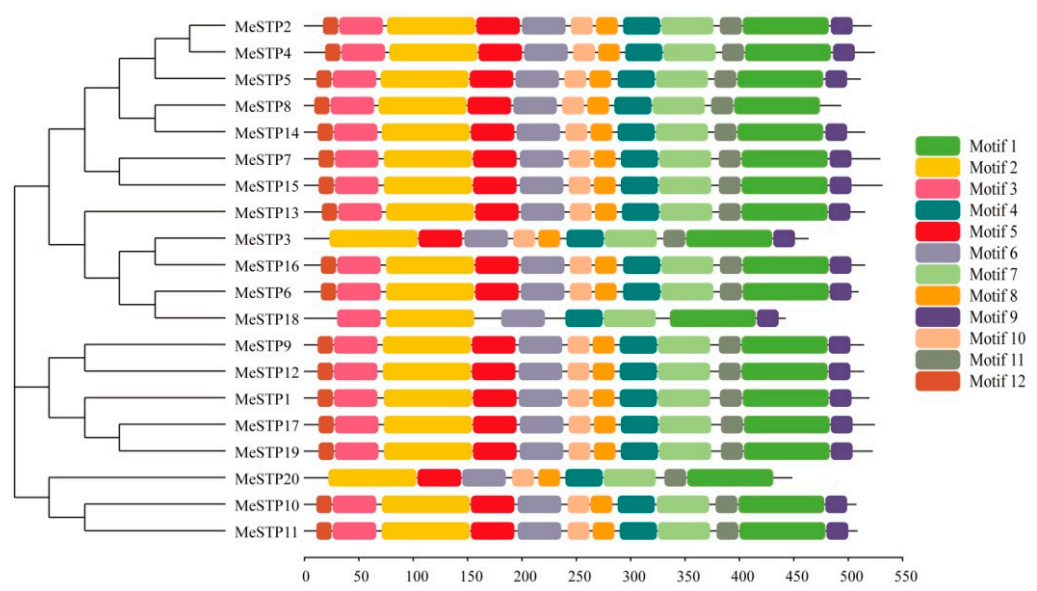

Figure 2. Conserved motifs of the MeSTP proteins identified by MEME. The gray lines represent the non-conserved sequences, and each motif is indicated by a colored box numbered at the bottom. The lengths of the motifs in each protein are proportional. The neighbor-joining phylogenetic tree of MeSTPs protein sequences was constructed using 1000 bootstrap replicates by MEGA 7.0. 
Table 2. Twelve different motifs commonly observed in cassava STP proteins.

\begin{tabular}{|c|c|c|c|}
\hline Motif & Length & Protein Sequences & Pfam Domain \\
\hline 1 & 80 & WSWGPLGWLVPSEIFPLETRSAGQSITVCVNMLFTFVIAQCFLTMLCHMKYGIF & \\
\hline \multirow{3}{*}{2} & & LFFAGWIVIMTIFVYFLLPETKNIPI & Sugar_tr \\
\hline & 82 & NNYCKYDNQYLQLFTSSLYLAALVASFFASYVTRKYGRKPSMQVGSISFCAGAI & \\
\hline & & LNAAAQNVWMLIIGRCLLGCGVGFANQA & Sugar_tr \\
\hline 3 & 41 & CMIAAMGGLMFGYDIGISGGVTSMDDFLKKFFPTVYRKKHH & Sugar_tr \\
\hline 4 & 35 & IPFFQQLTGINVIMFYAPVLFQTMGFGDDASLYSA & Sugar_tr \\
\hline 5 & 41 & VPLYLSEMAPPKYRGALNICFQLTITIGILIANLINYGTEK & Sugar_tr \\
\hline 6 & 41 & HPWGWRLSLGLAAVPALIMTVGSLFLPETPNSLIERGHHEE & Sugar_tr \\
\hline 7 & 49 & VITGAVNVISTLVSMYTVDKWGRRVLFLEAGIQMFICQVAVGCCLAAHF & Sugar_tr \\
\hline 8 & 21 & AKQVKHPWRNLMKRKYRPQLV & \\
\hline 9 & 21 & EEMDRVWKNHWFWKRYMDDDD & \\
\hline 10 & 21 & LKKIRGTDNVDEEFDDLVDAS & \\
\hline 11 & 21 & LPKGYAIFVVCMICVYVAGFA & \\
\hline 12 & 15 & AHDYEGKITPYVIVC & \\
\hline
\end{tabular}

\subsection{Phylogenetic Analysis of MeSTP Proteins}

A phylogenetic tree was constructed to analyze the evolutionary relationships among STP proteins from cassava, Arabidopsis, and castor bean. The results showed that the STP proteins could be classified into four groups, and MeSTPs grouped with AtSTPs and RcSTPs in each group (Figure 3). Among them, seven MeSTPs (MeSTP2, 4, 5, 7, 8, 14 and 15) together with four AtSTPs from Arabidopsis and six RcSTPs from castor bean were attributed to Group I (Figure 3). Group II consisted of five MeSTPs (MeSTP3, 6, 13, 16 and 18), two AtSTPs, and four RcSTPs (Figure 3). Three MeSTPs (MeSTP10, 11, and 20) clustered with two AtSTPs and three RcSTPs in Group III (Figure 3). Group IV contained five MeSTPs (MeSTP1, 9, 12, 17, and 19), six AtSTPs, and seven RcSTPs (Figure 3). Furthermore, a total of five sister pairs of MeSTPs were observed in the phylogenetic tree, including MeSTP2-MeSTP4, MeSTP6-MeSTP18, MeSTP7-MeSTP15, MeSTP9-MeSTP12, and MeSTP17-MeSTP19 (Figure 3).

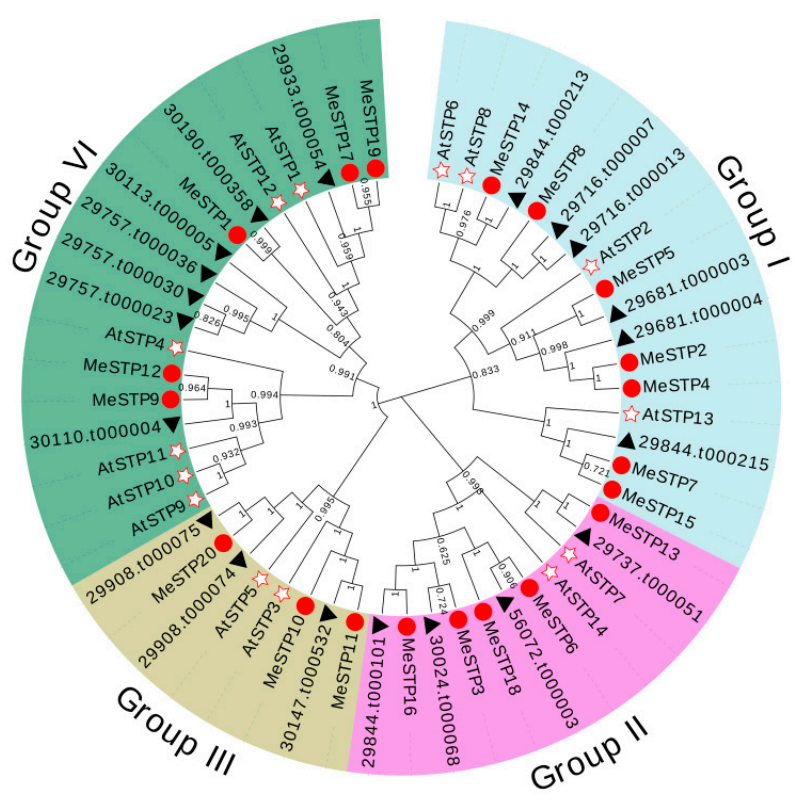

Figure 3. Phylogenetic relationship of STP proteins in three plant species. The evolutionary relationship is presented using a phylogenetic tree. STP proteins (MeSTP1-MeSTP20) from cassava, Arabidopsis thaliana (AtSTP1-AtSTP14), and Ricinus communis are marked with red circles, hollow stars, and black triangles, respectively. The accession numbers are listed in Supplementary Table S2. 


\subsection{Gene Duplication Analysis}

Subsequently, the tandem duplications and whole genome duplications (WGDs/segmental) of the MeSTP genes were analyzed. As shown in Figure 4, the MeSTP genes were differentially distributed on 11 out of 18 cassava chromosomes. Among these MeSTP genes, three pairs of genes, including MeSTP2-MeSTP4, MeSTP6-MeSTP18, and MeSTP17-MeSTP19, exhibited WGD/segmental duplication. Two pairs of genes, MeSTP4-MeSTP5 and MeSTP10-MeSTP11, were regarded as tandem duplication genes (Figure 4).

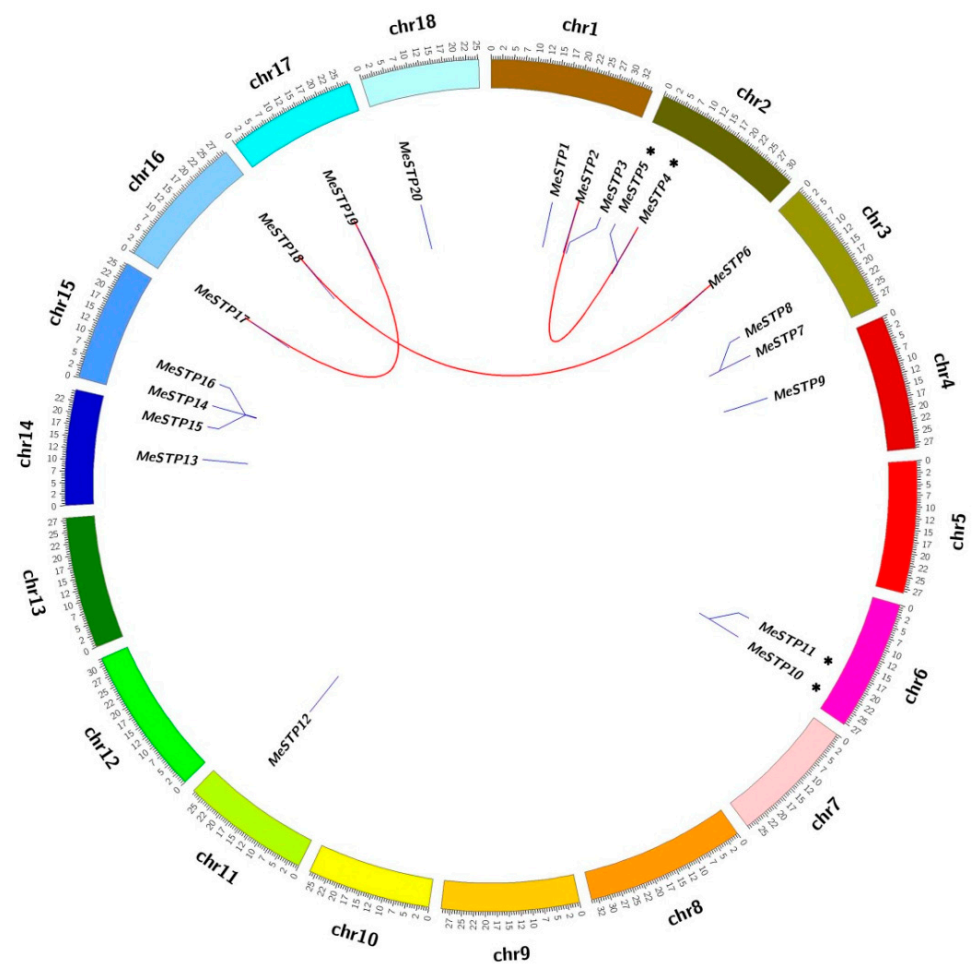

Figure 4. Chromosomal distribution and gene duplications of the MeSTP genes. The scale on the circle is in Megabases. Each colored bar represents a chromosome as indicated. Gene IDs are labeled on the basis of their positions on the chromosomes. The putative whole genome duplication (WGD) or segmental duplication genes are linked by a red line. Asterisks indicate tandem duplication.

\subsection{Expression Profiles of MeSTP Genes}

The cassava RNA-seq data from the GEO database, which were submitted by Wilson et al. [30], were used to explore the expression profiles of MeSTP genes in eleven tissues. As three MeSTPs (MeSTP1, MeSTP9, and MeSTP18) genes were not expressed in any tissues of cassava, the expression of the remaining 17 MeSTPS was considered for hierarchical clustering analysis. The results showed that MeSTP genes exhibited differential expression in various cassava tissues (Figure 5A). Among them, MeSTP2 and MeSTP20 exhibited tissue-specific expression in the sink tissue (fibrous root, FR), while MeSTP5 and MeSTP8 showed the highest expression in leaf (LF) and friable embryogenic callus (FEC), respectively (Figure 5A). Furthermore, six MeSTPs (MeSTP2, MeSTP7, MeSTP13, MeSTP15, MeSTP17, and MeSTP19) exhibited higher expression levels in a specific tissue compared to the remaining MeSTPs. For example, MeSTP2 showed a higher expression in the sink tissues (e.g., FR, lateral bud (LB), organized embryogenic structures (OES), shoot apical meristem (SAM), and storage root (SR)), while MeSTP17 displayed a higher expression in LF, midvein (MV), petiole, and stem, compared to the other MeSTP genes (Figure 5A). 


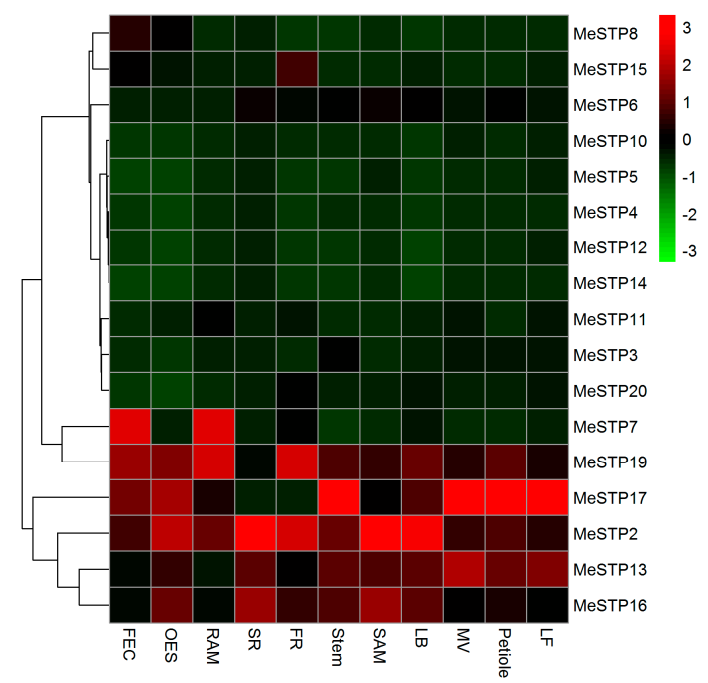

(A)

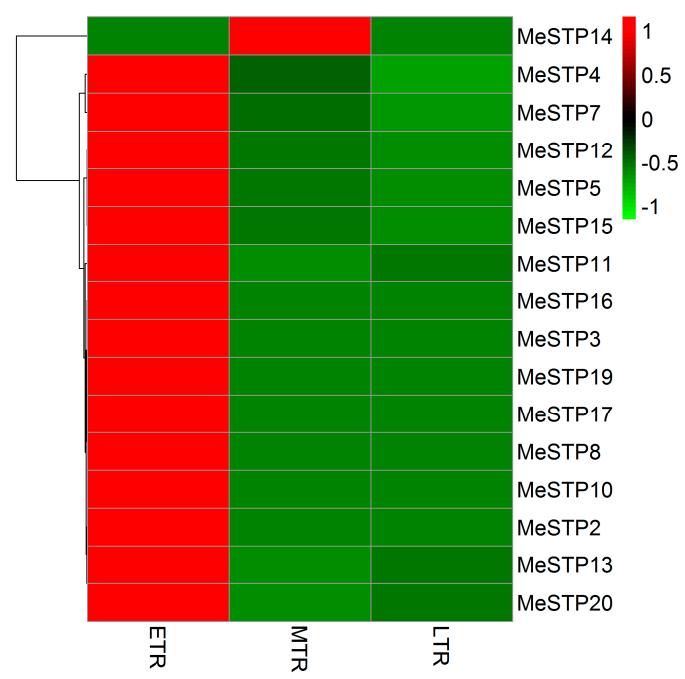

(B)

Figure 5. The expression profiles of MeSTP genes. The heat map of the MeSTP gene expression levels was hierarchically clustered using the R package "pheatmap" with the data normalization method of Z-score standardization. The color scale bar, ranging from green to red, represents low and high expression, respectively. (A) Expression profiles of MeSTP genes in 11 tissues, including friable embryogenic callus (FEC), somatic organized embryogenic structures (OES), root apical meristem (RAM), storage root (SR), fibrous root (FR), stem, shoot apical meristem (SAM), lateral bud (LB), midvein (MV), petiole, and leaf (LF); (B) expression profiles of MeSTP genes at the three different growth stages of roots, including the early storage root (ETR), the medium tuber root (MTR), and the late storage root (LTR).

Cassava RNA-seq data from the public SRA database submitted by the Chinese Academy of Tropical Agricultural Sciences [21] were used to dissect the expression profiles of MeSTPs in the roots at three growth stages. As four MeSTPs (MeSTP1, MeSTP6, MeSTP9, and MeSTP18) were not expressed in the roots at any growth stages, a total of $16 \mathrm{MeSTP}$ genes were used for further analysis (Figure 5B). The results showed that 15 out of $16 \mathrm{MeSTP}$ genes were mainly expressed in the early storage roots, followed by the medium tuber root, and the late storage roots (Figure 5B). For example, the expression level of MeSTP2 in the early storage roots was 11-fold and 10-fold higher than that in the medium tuber roots and the late storage roots, respectively (Figure 5B).

Subsequently, a qRT-PCR analysis was performed to verify the expression of 16 MeSTPs, as outlined in the previous paragraph, in the roots at $30,40,45$, and 51 days of growth. The results showed that most of the MeSTPs displayed higher expression in the roots at 30 and 40 days of growth (Figure 6). For example, eight MeSTPs and seven MeSTPs showed higher expression in the roots at 30 and 40 days of growth, respectively, compared to their expression in the roots at a later stage (Figure 6). Furthermore, all of the tested MeSTPS exhibited decreased expression in the roots after 45 days of growth, except for MeSTP2, which displayed the highest expression in the roots at 45 days of growth, followed by a decreased expression at 51 days of growth (Figure 6). These results suggest that some of the MeSTP genes may be involved in the early root growth. 

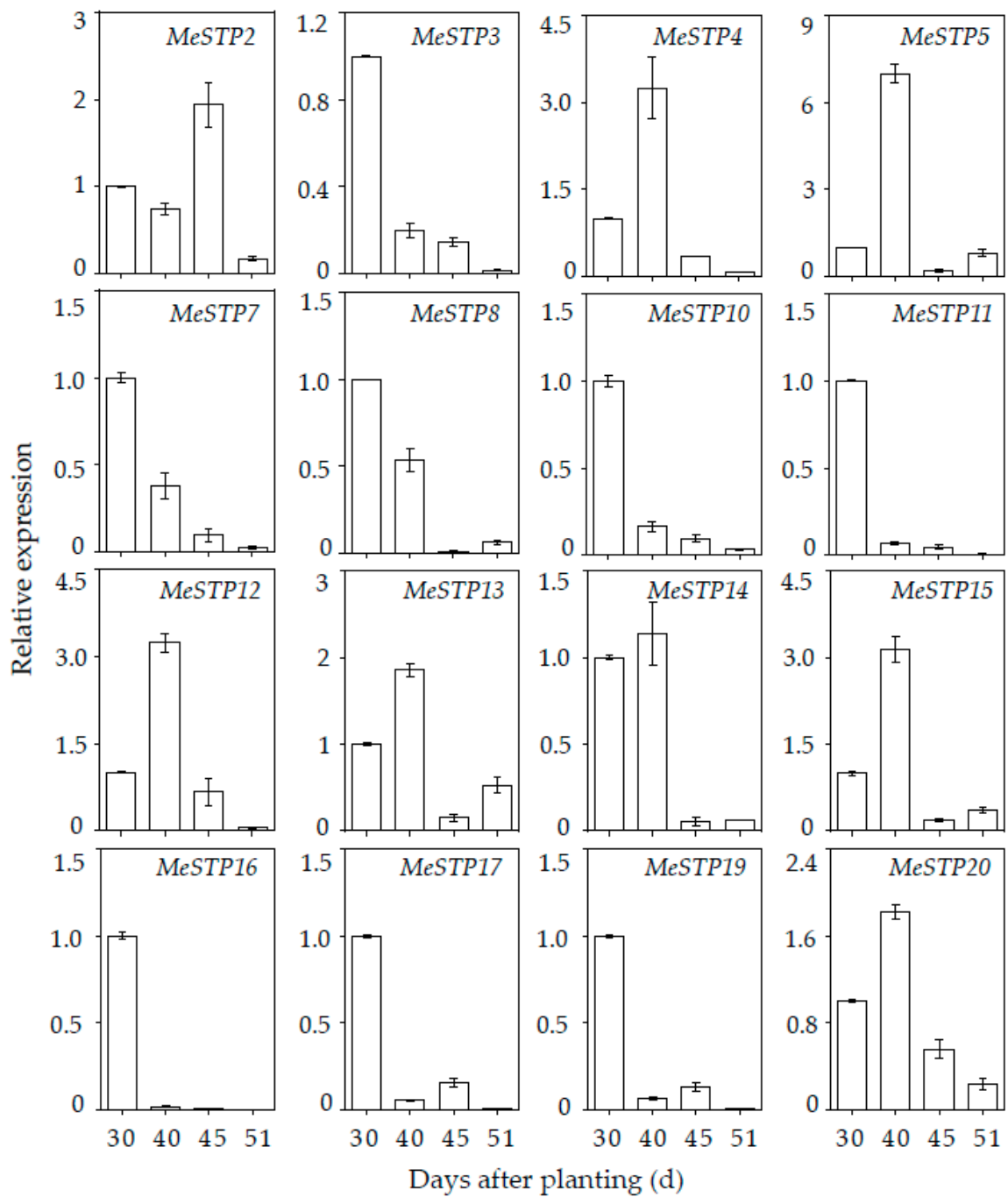

Figure 6. Expression patterns of sixteen MeSTP genes in the roots. qRT-PCR was conducted to analyze MeSTP gene expression in the roots at 30,40,45, or 51 days of growth in normal conditions. The gene expression in the roots at 30 days of growth was set to one, and the expression level of each gene was normalized with respect to its expression in the roots at 30 days of growth.

\subsection{Complementation Analysis of MeSTPs in a Yeast Strain Defective in Monosaccharide Uptake}

To further analyze and compare the monosaccharide transport activity of MeSTPs, 16 out of $20 \mathrm{MeSTPs}$ were successfully cloned and separately introduced into yeast strain EBY.VW4000, which is deficient in monosaccharide uptake ability. Five monosaccharide substrates, including glucose, fructose, mannose, galactose, and xylose, were used to examine the sugar transport activity of MeSTPs. As shown in Figure 7, all yeast cells grew well on synthetic deficient (SD) media containing $2 \%$ maltose, suggesting the presence of the expression vectors containing the target genes. The control yeast cells transformed with empty vector pDR195 could not grow on SD medium containing any of the tested monosaccharides (Figure 7). Among the yeast cells carrying MeSTPs, three MeSTP members (MeSTP2, 15, and 19) could efficiently complement the yeast mutant in the SD medium containing the five tested monosaccharides, while MeSTP5, MeSTP8, and MeSTP11 transformants grew weakly but much better than the pDR195 control when supplied with these monosaccharide substrates. Three MeSTP (MeSTP7, 12, and 17) transformants grew well on SD medium supplemented with mannose, galactose, glucose, and fructose, but not xylose. However, yeast cells carrying MeSTP3 and MeSTP16 only grew on SD medium containing galactose, suggesting that these two MeSTP proteins 
function as galactose-specific transporters in yeast. Furthermore, the remaining five MeSTP members (MeSTP4, 10, 13, 14, and 20) failed to induce yeast growth on SD medium containing the five tested monosaccharides (Figure 7), suggesting that these five MeSTP members could not transport these substrates in yeast.

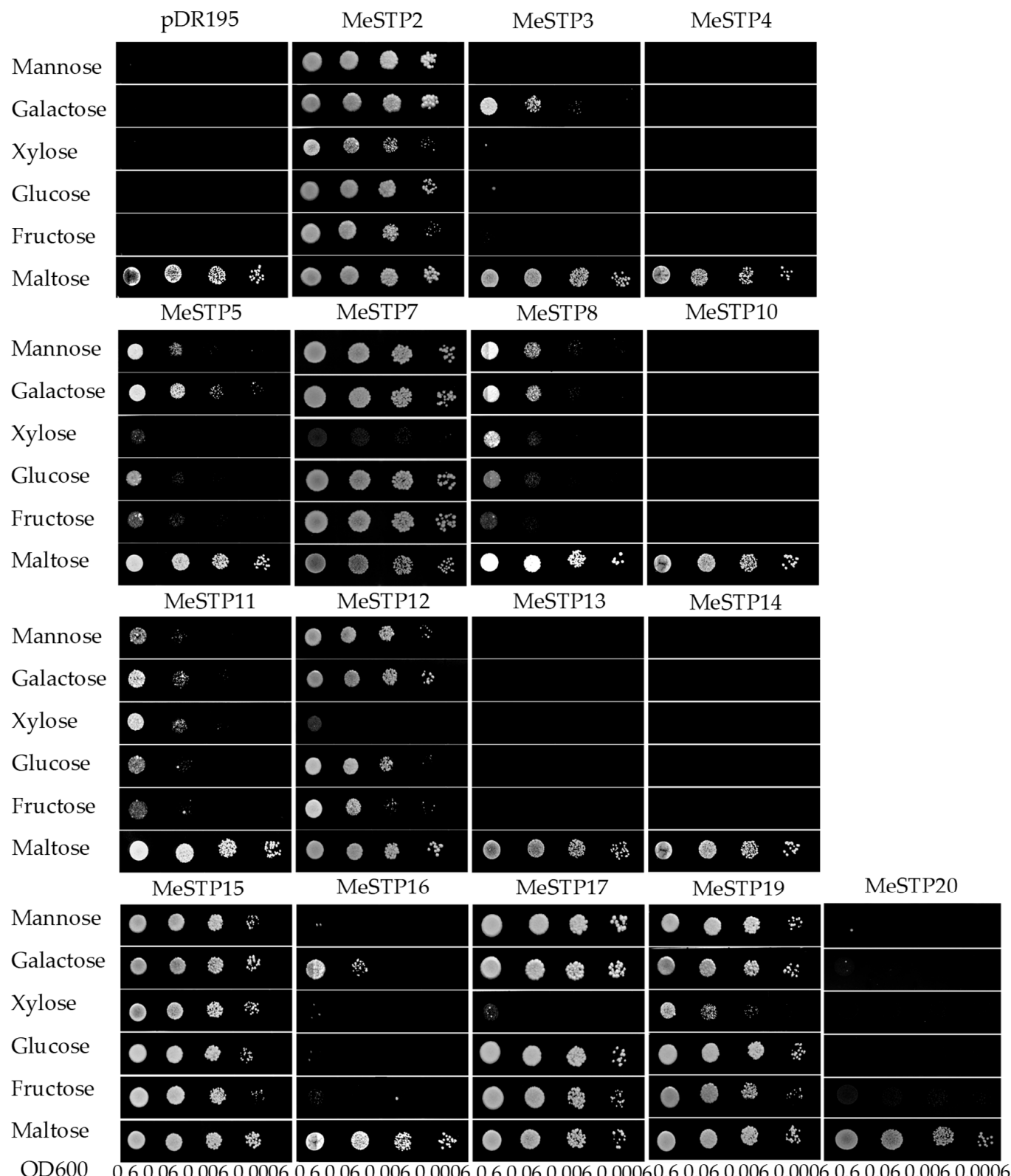

Figure 7. Complementation of yeast EBY. VW4000 mutant by MeSTP genes. Yeast cell suspensions with optical density (OD) at $600 \mathrm{~nm}$ of 0.6 and three corresponding 1:10 dilutions were dropped on solid SD-ura medium containing $2 \%$ mannose, galactose, xylose, glucose, or fructose for 3 days at $27^{\circ} \mathrm{C}$; pDR195 indicates yeast cells transformed with the empty vector pDR195.

\subsection{Subcellular Localization of MeSTPs}

To analyze the subcellular localization of MeSTP proteins, MeSTP-GFP fusion proteins were transiently expressed in cassava mesophyll protoplasts. The results showed that the signal of GFP in cells transfected with the empty vector was mainly detected in the cytoplasm and plasma membrane, whereas the GFP signals in cells expressing the 16 MeSTP fusion proteins were confined to the plasma membrane (Figure 8), suggesting that these MeSTPs might be membrane proteins. 


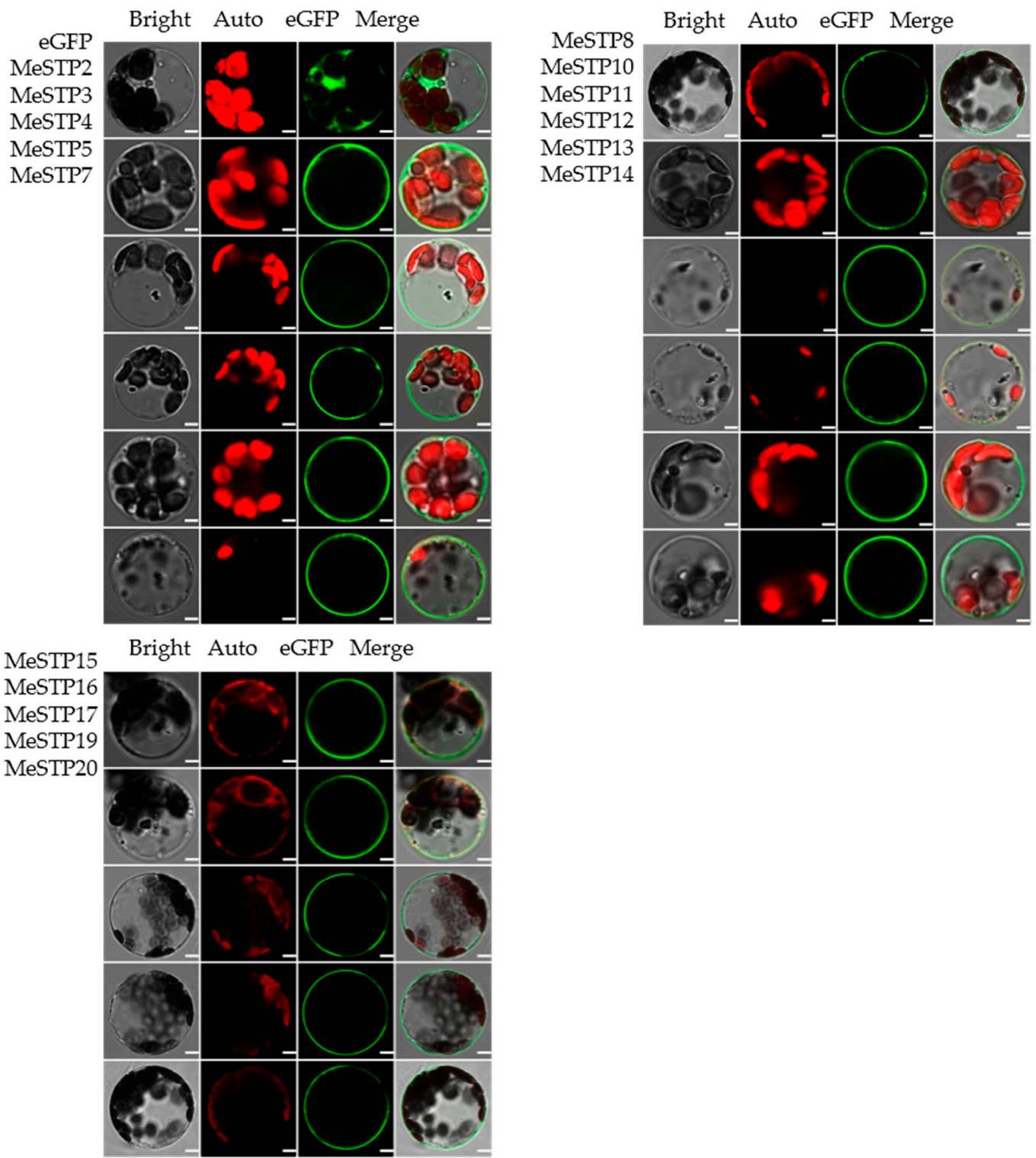

Figure 8. Subcelluar localization of MeSTPs proteins in cassava mesophyll protoplasts. The cassava mesophyll protoplasts expressing the empty vector $\mathrm{pX-DG}$ were used as a control. Bright-field images (Bright), chlorophyll autofluorescence (Auto), fluorescence of eGFP fusion protein (eGFP), and te merged images (Merge) were examined using laser-scanning confocal microscopy. Bars $=5 \mu \mathrm{m}$.

\section{Discussion}

STP proteins in model plants, such as Arabidopsis and rice, have been shown to play critical roles in sugar transport [6,31]. However, the genome-wide expression profile of the STP gene family is less well defined in other crops, such as cassava, which is characterized by a high starch content in the roots. The release of a high-quality cassava genome provides an opportunity to explore the MeSTP gene family and to dissect its potential roles in root growth. In this study, gene structure, gene duplications, and protein motifs of the MeSTP family were globally analyzed in cassava for the first time. Furthermore, the expression pattern and function analysis of the MeSTP genes were further investigated.

A total of $20 \mathrm{MeSTP}$ genes were identified in the cassava genome through a BLAST search and HMMER analysis (Table 1). Most of the cassava STP proteins harbored a Sugar_tr domain (PF00083) belonging to the major facilitator superfamily (MFS) (Table 2). MFS transporters in plants possess 
a common structure of 12 transmembrane domains (TMD1-TMD12), which are separately contained within the N-domain (TMD1-TMD6) and the C-domain (TMD7-TMD12) [4,32]. In the current study, 10 out of 20 MeSTP proteins contained the entire 12 TMDs, while 8 MeSTP members possessed 10 or 11 TMDs. However, MeSTP18 carried only eight TMDs, displaying a sequence deletion in the middle of the protein (Table 1). These results suggest that loss of the $\mathrm{N}$-terminal or C-terminal regions may have occurred in some MeSTP members during evolution. Consistent with this, similar STP protein structures are also observed in tomato and grape $[9,10]$. Furthermore, most of the MeSTP genes contained four exons and three introns, except for seven MeSTPS (MeSTP7, MeSTP8, MeSTP10, MeSTP11, MeSTP15, MeSTP18, and MeSTP20), which displayed variations in the numbers of exons and introns (Figure 1). Similarly, the numbers of exons and introns in STP genes have been demonstrated to range from three to five in other plant species, such as Arabidopsis, grape, and pears $[6,9,11]$. The variations in STP gene structure might be due to structural divergence mechanisms, such as the insertion or deletion of exons and introns as well as exonization and pseudoexonization, as suggested by $\mathrm{Xu}$ et al. [33]. Interestingly, most of the MeSTPs are basic proteins with $\mathrm{pI}$ values greater than 7 , except for MeSTP14 which has a $\mathrm{pI}$ value of 6.84. This may be due to the fact that MeSTP14 has a higher proportion of acidic amino acids, including 20 aspartic acids and 22 glutamic acids, which are more than those present in the other MeSTP proteins.

A phylogenetic analysis revealed that the 20 MeSTPs together with the other STP proteins from Arabidopsis and castor bean were classified into four groups, and the MeSTPs grouped with AtSTPs and RcSTPs in each group (Figure 3), suggesting a close relationship between the STPs of these three species and that STP proteins are highly conserved across lineages. Group I contained seven MeSTPs (MeSTP2, 4, 5, 7, 8, 14, and 15), four AtSTPs, and six RcSTPs (Figure 3). Among the AtSTPs belonging to this group, AtSTP6, which exhibited high similarity to MeSTP14, is a high-affinity $\mathrm{H}^{+}$/monosaccharide transporter with broad-spectrum substrates, mainly expressed in pollen at the late stage of development [34]. As the homologous gene of MeSTP7 and MeSTP15, AtSTP13 has been characterized as a high-affinity hexose-specific $/ \mathrm{H}^{+}$transporter expressed in the vascular tissue [14]. Overexpression of AtSTP13 increases plant biomass through the regulation of carbon and nitrogen metabolism [35]. MeSTP10 and MeSTP11 clustered with AtSTP3 in group III (Figure 3). AtSTP3 is a low-affinity energy-dependent $\mathrm{H}^{+}$symporter detected in green leaves, and the expression of AtSTP3 is induced by wounding [15]. In group IV, AtSTP1 is a guard cell-specific localization gene involved in carbon acquisition and plays a possible role in osmoregulation [31]. AtSTP11 is reported to be a pollen tuber-specific monosaccharide transporter, participating in the allocation of sugars to growing pollen tubes [36]. Therefore, MeSTP proteins clustered with the characterized STP proteins in the same group possibly possess similar biochemical properties. Additionally, a close relationship between the STP members from cassava and castor bean was observed in the phylogenetic tree, reflecting the fact that both cassava and castor bean are members of the Euphorbiaceae family, as discussed by Bredeson et al. [37].

In cassava, all of the $20 \mathrm{MeSTP}$ genes exhibited differential localization on 18 chromosomes, with some homologous gene pairs (Figures 3 and 4). Among them, three gene pairs (MeSTP2-MeSTP4, MeSTP6-MeSTP18, and MeSTP17-MeSTP19) were determined to be a product of WGD/segmental duplication, whereas two pairs (MeSTP4-MeSTP5 and MeSTP10-MeSTP11) were possibly involved in tandem duplication (Figure 4), which is similar to previously reported results in pear according to which six PbSTPs could be assigned to WGD/segmental duplication, while five PbSTPs were regarded as tandem duplication events [11]. Gene duplication is considered to be the primary driving force for evolution, leading to functional speciation and diversification [38,39]. In this study, the result of gene duplication analysis indicated that the MeSTP family has increased rapidly during the course of evolution and that WGD/segmental events have largely contributed to the expansion, accompanied by tandem duplications.

The STP genes function in the distribution of monosaccharides, which is further involved in diverse metabolic processes during plant growth and development [40]. Cassava RNA-seq data from 
public databases were further explored to dissect the expression profiles of the MeSTP genes in this study. The results showed that MeSTP genes exhibited differential expressions in various cassava tissues (Figure 5A). Similarly, STP genes in Arabidopsis also display different expression patterns in various tissues. For example, AtSTP1 shows specific expression in the roots and is the major transporter for the uptake of external hexose [12]. AtSTP3 exhibits leaf-specific expression and may participate in the retrieval of sugars lost from the cytoplasm by passive leakage [15]. In this study, some of the MeSTP genes exhibited tissue-specific expression, such as MeSTP2 and MeSTP20, which were mainly expressed in the fibrous root, while MeSTP5 was specifically expressed in the leaf (Figure 5A). Furthermore, among the 20 MeSTP genes, MeSTP2 showed the highest expression in the sink tissues (e.g., fibrous root and storage root), and MeSTP17 displayed the highest expression in leaf, midvein, petiole, and stem (Figure 5A). In tomato, among different LeHT genes, LeHT2 shows the highest expression in source leaf, suggesting a possible role of this gene in retrieving cell wall hydrolysis products [41]. The tissue-specific expression analysis of the MeSTP genes provides evidence of the potential functions of these gene in specific tissues.

As monosaccharides (e.g., glucose, fructose, and mannose) are important to generate energy and synthesize cellulose and starch, which are further accumulated in the roots of cassava [40], it is important to investigate the expression profiles of MeSTP genes in the roots of cassava and dissect the potential roles of these genes in sugar distribution. The expression profiles from the RNA-seq data revealed that most of the MeSTP genes are mainly expressed in the roots at early growth stages (Figure 5B). As the expression of STP genes is always coupled with that of cell wall invertase genes [2], it can be speculated that sucrose is hydrolyzed in the apoplast by cell wall invertases into monosaccharides and is further transported to the roots by MeSTPs at the early root growth stage. However, with the roots developing, a conversion of the sucrose unloading strategy occurs from the apoplastic pathway to the symplastic pathway, which is based on plasmodesmatas and does not employ sugar transporters. This kind of switch was also observed during tuberization in potato and thought to be essential for rapid starch accumulation in developing roots [42]. To study the expression of MeSTPs genes in more detail at the early storage root stage, a qRT-PCR analysis was executed. The result revealed that most of the MeSTPS displayed higher expression in roots at 30 and 40 days of growth, followed by decreased expression in roots at later growth stages (Figure 6), which further confirmed the in silico data. As the root is a typical sink organ, its development depends on the photoassimilates supplemented from the phloem. The highly expressed MeSTPs may function primarily in post-phloem carbohydrate unloading, regulating energy availability for roots growth. Similarly, it has been demonstrated that AtSTP1 and AtSTP13 exhibit higher expression in the roots of Arabidopsis, with the possible function of reabsorbing monosaccharides [43]. Furthermore, AtSWEET4 is characterized as a plasma membrane localization transporter mainly expressed in the stele of roots [44]. In Medicago truncatula, Mest1 (monosaccharide transporter) shows a root tissue-specific expressing pattern to satisfy the high requirement for hexoses in elongating cells [45]. Therefore, MeSTP genes exhibiting higher expression in the roots at the early growth stage may be involved in root growth.

In this study, we failed to detect the expression of MeSTP1, 6, 9, and MeSTP18 in different tissues, development periods, or after stress treatments, thus we could not clone these four full-length genes. It is possible that these four MeSTPS are pseudo-genes encoding non-functional sugar transporters. The monosaccharide transport activity of other 16 MeSTPs proteins was further analyzed in a yeast mutant defective in monosaccharide uptake. Most of MeSTPs displayed variations in monosaccharide transport activity despite their similar plasma membrane localization (Figures 7 and 8). Among these MeSTPs, six MeSTP members (MeSTP2, 5, 8, 11, 15, and 19) were able to complement the phenotype of the yeast mutant in the SD medium supplemented with the five tested monosaccharides (Figure 7), suggesting that these MeSTPs transport a broad spectrum of monosaccharide substrates, contributing to general sugar distribution in the roots of cassava. Furthermore, three MeSTP members (MeSTP7, 12, and 17) showed a strong ability to transport 
mannose, galactose, glucose, and fructose, but not xylose, and MeSTP3 and MeSTP16 exhibited galactose-specific transport activity (Figure 7). The monosaccharides uptake by MeSTPs might be subsequently involved in complex metabolic activities, cell wall reconstruction, or starch synthesis during cassava tuber root growth. For example, it has been reported that Mest1 in Medicago is involved in glucose and fructose transportation, facilitating the acquisition of hexoses in root elongating cells [45]. Furthermore, overexpression of AtSWEET4, a plasma membrane localization transporter, in Arabidopsis leads to increasing root growth through the regulation of glucose and fructose uptake from the extracellular space [44]. Therefore, these results suggest that MeSTPs might be vital to monosaccharides distribution, regulating the early tuber root growth of cassava, a hypothesis that merits further study.

\section{Materials and Methods}

\subsection{Plant Materials}

Cassava cultivar "Ku50" was used as plant material in this study. All the cutting seed-stems were normally planted in the field, and the roots were harvested at 30, 40, 45, and 51 days after planting, when the tuber started to form. Furthermore, different cassava tissues, such as leaves, stems, roots, flowers, and seeds were also collected for the preparation of the mixed cDNA template, which was further used for MeSTPs cloning. After freezing in liquid nitrogen, all fresh materials were preserved at $-80^{\circ} \mathrm{C}$ for further total RNA isolation.

\subsection{Identification of the STP Genes in Cassava}

To identify STP genes in cassava, the whole-genome data of cassava (Manihot esculenta v6.1) were downloaded from the Phytozome website (https://phytozome.jgi.doe.gov/pz/portal.html). The HMMER profile of the Sugar_tr domain (PF00083) from Pfam (http://pfam.sanger.ac.uk/) was used to search the cassava protein database at a standard E-value $<1 \times 10^{-5}$, according to Finn et al. [46]. A total of 24 putative STP proteins were identified. Furthermore, the protein sequences of 14 Arabidopsis AtSTPs and 29 rice OsSTPs were used in a BLAST search against the 24 putative STP proteins to find their best match sequences. Finaly, a total of 20 STP protein sequences were identified in the cassava genome. The STP genes were named MeSTP1 to MeSTP20 according to their positions on cassava chromosomes.

\subsection{Gene Structure, Conserved Motifs, and Phylogenetic Analysis}

The Gene Structure Display Server (http:/ /gsds.cbi.pku.edu.cn/) was used for the MeSTP gene structure analysis. MeSTP protein conserved motifs were analyzed by the MEME and Pfam programs according to the published method of Bailey et al. [47]. MEME was employed using the following parameters: optimum width, 20-60; number of repetitions, any; maximum number of motifs, 12 . A phylogenetic tree was constructed based on protein sequence alignment of the 20 MeSTPs, 20 castor bean RcSTPs, and 14 Arabidopsis AtSTPs, through PHYML program using the maximum likelihood (ML) method with 1000 bootstrap replicates, and GTR + I + G was selected as the testing model. Furthermore, neighbor-joining (NJ) phylogenetic trees of the MeSTPs gene and protein sequences were constructed using MEGA7 software with 1000 bootstrap resamplings.

\subsection{Gene Duplication Analysis}

The MCScanX program was used to identify MeSTP duplications as previously described by Wang et al. [48]. In brief, 33,033 protein sequences from cassava were analyzed using an all-vs-all BLAST search with e-value $<1 \times 10^{-5}$, and the output file format was set to m8. With the BLAST outputs, gene positions file, and the execution of MCScanX program, all genes were classified into various types of duplications. A schematic diagram of the putative duplications of the MeSTP genes 
was constructed using the Circos software [49], and then the putative WGDs/segmental duplications of MeSTPs were connected by links.

\subsection{Expression Profiles of MeSTP Genes in RNA-Seq Data}

To explore the expression profiles of MeSTPs in different cassava tissues, the fragments-per-kilobase-per-million fragments mapped (FPKM) values of the MeSTP genes were obtained from the genome-wide RNA-seq dataset in the Gene Expression Omnibus (GEO) (accession number: GSE82279) submitted by Wilson et al. [30]. Hierarchical clustering was performed using the R package "pheatmap" with the data normalization method of Z-score standardization. The 11 selected cassava tissues were as follows: friable embryogenic callus (FEC), somatic organized embryogenic structures (OES), root apical meristem (RAM), storage root (SR), fibrous root (FR), stem, shoot apical meristem (SAM), lateral bud (LB), midvein (MV), petiole, and leaf (LF).

To explore the expression profiles of MeSTPs in roots at different growth stages, including the early storage root (75 days), the medium tuber root (120 days), and the late storage root (150 days), the public high-throughput RNA-seq read archive (SRA) databases of the cassava cultivar "KU50" submitted by the Chinese Academy of Tropical Agricultural Sciences [21] were used. The FASTX-toolkit program (version 0.0.13, http:/ / hannonlab.cshl.edu/fastx_toolkit/) was used to remove the adapter sequence from the raw sequence reads. The obtained clean reads were aligned to the cassava reference genome (version 6.1) derived from the Phytozome website, using Tophat 2.0.11 with default parameters [50]. The FPKM values were calculated by Cufflinks as described by Trapnell et al. [51]. Hierarchical clustering was performed as described above.

\subsection{Quantitative RT-PCR ( $q R T-P C R$ ) Analysis of MeSTP Genes}

Total RNA from the roots of the cassava cultivar "KU50" was extracted using RNAplant Plus reagent (Tiangen, China) according to the manual. First-strand cDNA was synthesized from $2 \mu \mathrm{g}$ of DNase-treated RNA using M-MLV reversed transcriptase (Promega, Madison, WI, USA). SYBR Premix Ex Taq II (Takara, Japan) was used for the qRT-PCR analysis, which was monitored on an Applied Biosystems 7500 Real-Time PCR system (Thermo, Waltham, MA, USA). The specific primer pairs of 20 MeSTP genes used for qRT-PCR analysis are shown in Supplementary Table S1. The relative expression levels were calculated by the $2^{-\Delta \Delta C t}$ method [52]. Each gene expression analysis had three biological replicates.

\subsection{Complementation Analysis of MeSTPs in Yeast (Saccharomyces cerevisiae)}

The open reading frames (ORFs) of MeSTP genes were amplified from cassava cDNA libraries constructed by Phusion High-Fidelity DNA Polymerase (Thermo, USA) using gene-specific primers (Supplementary Table S2). The amplified products were gel-purified and cloned into the yeast shuttle vector pDR195 using the Clontech In-Fusion PCR Cloning Kit (Takara, Japan). Vector pDR195 contains the URA3 as a selective marker and the Pma1 promoter for constitutive expression of the target gene.

The yeast strain EBY. VW4000, which is deficient in hexose transport as a result of the multiple knock-out of endogenous transporters [53], was used to analyze the functions of MeSTP genes. The plasmid constructs were transferred into EBY.VW4000 as described by Morita et al. [54]. Yeast cells transformed with the empty vector pDR195 was used as a control. The transformed cells were first precultured in liquid synthetic deficient (SD)-ura medium supplemented with $2 \%$ maltose as the sole carbon source until the $\mathrm{OD}_{600}$ value reached 0.6 . Three serial dilutions $(10 \times)$ of yeast cells were dropped on solid SD-ura medium containing $2 \%$ maltose or different monosaccharide substrates (including mannose, galactose, xylose, glucose, and fructose) and cultured for 3 days at $27^{\circ} \mathrm{C}$.

\subsection{Subcellular Localization of MeSTP}

The ORFs of MeSTP genes were amplified using gene-specific primers (Supplementary Table S3) and then cloned into pX-DG vector fused with GFP (green fluorescent protein) according to 
Chen et al. [55]. The plasmid constructs were then transiently expressed in cassava mesophyll protoplasts as previously described by $\mathrm{Wu}$ et al. [56]. The GFP fluorescence was imaged using a confocal laser scanning microscope (Leica TCS SPII, Leica Microsystems, Wetzlar, Germany).

\section{Conclusions}

In this study, a total of $20 \mathrm{MeSTP}$ genes were identified in a genome-wide survey of the cassava genome. All MeSTPS were classified into four groups and contained the Sugar_tr conserved motifs. Gene duplication analysis showed that WGD/segmental and tendem duplications were involved in the expansion of the MeSTP genes. The RNA sequencing results of 11 tissues of cassava indicated that MeSTPS is essential for the development of mutiple tissues in cassava. Furthermore, comparisons of the expression levels of the MeSTP genes during storage root development showed that MeSTPS are mainly expressed at the early storage root, indicating that there may be a switch in sucrose unloading pathways during the maturation of the storage root. Our results of qRT-PCR, monosaccharide transport activity, and subcellular localization of MeSTPs, confirm that MeSTPs are plasma membrane localization transporters critical to monosaccharides distribution, which regulate early tuber root growth in cassava.

Supplementary Materials: Supplementary materials can be found at http:/ /www.mdpi.com/1422-0067/19/4/ 987/s1.

Acknowledgments: This work was supported by grants from the National Natural Science Foundation of China (31660412), Core Research Budget of the Non-profit Governmental Research Institution (1630032016008), Funds of the modern agricultural industry technology system (CARS-HNCYH), and Comprehensive Strength Promotion Plan of College in the Western Regions (M8K3124001001003002).

Author Contributions: Lijuan Luo and Qin Liu conceived and designed the research. Qin Liu, Huijie Dang, Zhijian Chen, and Junzheng Wu performed the experiments. Qin Liu and Huijie Dang carried out genes expression analysis. Qin Liu, Yinhua Chen, Songbi Chen and Lijuan Luo analyzed the data. All authors contributed to writing this manuscript and approved its final version.

Conflicts of Interest: The authors declare no conflict of interest.

\section{References}

1. Smeekens, S.; Hellmann, H.A. Sugar sensing and signaling in plants. Front. Plant Sci. 2014, 5, 113. [CrossRef] [PubMed]

2. Rennie, E.A.; Turgeon, R. A comprehensive picture of phloem loading strategies. Proc. Natl. Acad. Sci. USA 2009, 106, 14162-14167. [CrossRef] [PubMed]

3. Ludewig, F.; Flügge, U.-I. Role of metabolite transporters in source-sink carbon allocation. Front. Plant Sci. 2013, 4, 231. [CrossRef] [PubMed]

4. Yan, N. Structural advances for the major facilitator superfamily (MFS) transporters. Trends Biochem. Sci. 2013, 38, 151-159. [CrossRef] [PubMed]

5. Sauer, N.; Tanner, W. The hexose carrier from Chlorella: CDNA cloning of a eucaryotic $\mathrm{H}^{+}$-cotransporter. FEBS Lett. 1989, 259, 43-46. [CrossRef]

6. Büttner, M. The Arabidopsis sugar transporter (AtSTP) family: An update. Plant Biol. 2010, $12,35-41$. [CrossRef] [PubMed]

7. Toyofuku, K.; Kasahara, M.; Yamaguchi, J. Characterization and expression of monosaccharide transporters (OsMSTs) in rice. Plant Cell Physiol. 2000, 41, 940-947. [CrossRef] [PubMed]

8. Johnson, D.A.; Thomas, M.A. The monosaccharide transporter gene family in Arabidopsis and rice: A history of duplications, adaptive evolution, and functional divergence. Mol. Biol. Evol. 2007, 24, 2412-2423. [CrossRef] [PubMed]

9. Afoufa-Bastien, D.; Medici, A.; Jeauffre, J.; Coutos-Thevenot, P.; Lemoine, R.; Atanassova, R.; Laloi, M. The Vitis vinifera sugar transporter gene family: Phylogenetic overview and macroarray expression profiling. BMC Plant Biol. 2010, 10, 245. [CrossRef] [PubMed]

10. Reuscher, S.; Akiyama, M.; Yasuda, T.; Makino, H.; Aoki, K.; Shibata, D.; Shiratake, K. The sugar transporter inventory of tomato: Genome-wide identification and expression analysis. Plant Cell Physiol. 2014, 55, 1123-1141. [CrossRef] [PubMed] 
11. Li, J.-M.; Zheng, D.-M.; Li, L.-T.; Qiao, X.; Wei, S.-W.; Bai, B.; Zhang, S.-L.; Wu, J. Genome-wide function, evolutionary characterization and expression analysis of sugar transporter family genes in pear (Pyrus bretschneideri Rehd). Plant Cell Physiol. 2015, 56, 1721-1737. [CrossRef] [PubMed]

12. Sherson, S.M.; Hemmann, G.; Wallace, G.; Forbes, S.; Germain, V.; Stadler, R.; Bechtold, N.; Sauer, N.; Smith, S.M. Monosaccharide/proton symporter AtSTP1 plays a major role in uptake and response of Arabidopsis seeds and seedlings to sugars. Plant J. 2000, 24, 849-857. [CrossRef] [PubMed]

13. Truernit, E.; Schmid, J.; Epple, P.; Illig, J.; Sauer, N. The sink-specific and stress-regulated Arabidopsis STP4 gene: Enhanced expression of a gene encoding a monosaccharide transporter by wounding, elicitors, and pathogen challenge. Plant Cell 1996, 8, 2169-2182. [CrossRef] [PubMed]

14. Nørholm, M.H.; Nour-Eldin, H.H.; Brodersen, P.; Mundy, J.; Halkier, B.A. Expression of the Arabidopsis high-affinity hexose transporter STP13 correlates with programmed cell death. FEBS Lett. 2006, 580, 2381-2387. [CrossRef] [PubMed]

15. Büttner, M.; Truernit, E.; Baier, K.; Scholz-Starke, J.; Sontheim, M.; Lauterbach, C.; Huss, V.; Sauer, N. AtSTP3, a green leaf-specific, low affinity monosaccharide- $\mathrm{H}^{+}$symporter of Arabidopsis thaliana. Plant Cell Environ. 2000, 23, 175-184. [CrossRef]

16. Mendgen, K.; Hahn, M. Plant infection and the establishment of fungal biotrophy. Trends Plant Sci. 2002, 7, 352-356. [CrossRef]

17. Yamada, K.; Saijo, Y.; Nakagami, H.; Takano, Y. Regulation of sugar transporter activity for antibacterial defense in Arabidopsis. Science 2016, 354, 1427-1430. [CrossRef] [PubMed]

18. Consortium, I.C.G.M. High-resolution linkage map and chromosome-scale genome assembly for cassava (Manihot esculenta Crantz) from 10 populations. G3 Genes Genomes Genet. 2015, 5, 133-144.

19. Ziska, L.H.; Runion, G.B.; Tomecek, M.; Prior, S.A.; Torbet, H.A.; Sicher, R. An evaluation of cassava, sweet potato and field corn as potential carbohydrate sources for bioethanol production in Alabama and Maryland. Biomass Bioenergy 2009, 33, 1503-1508. [CrossRef]

20. Jansson, C.; Westerbergh, A.; Zhang, J.; Hu, X.; Sun, C. Cassava, a potential biofuel crop in (the) People's Republic of China. Appl. Energy 2009, 86, S95-S99. [CrossRef]

21. Wang, W.; Feng, B.; Xiao, J.; Xia, Z.; Zhou, X.; Li, P.; Zhang, W.; Wang, Y.; Møller, B.; Zhang, P. Cassava genome from a wild ancestor to cultivated varieties. Nat. Commun. 2013, 5, 5110. [CrossRef] [PubMed]

22. Reilly, K.; Bernal, D.; Cortés, D.F.; Gómez-Vásquez, R.; Tohme, J.; Beeching, J.R. Towards identifying the full set of genes expressed during cassava post-harvest physiological deterioration. Plant Mol. Biol. 2007, 64, 187-203. [CrossRef] [PubMed]

23. Yang, J.; An, D.; Zhang, P. Expression profiling of cassava storage roots reveals an active process of glycolysis/gluconeogenesis. J. Integr. Plant Biol. 2011, 53, 193-211. [CrossRef] [PubMed]

24. Lopez, C.; Soto, M.; Restrepo, S.; Piégu, B.; Cooke, R.; Delseny, M.; Tohme, J.; Verdier, V. Gene expression profile in response to Xanthomonas axonopodis pv. manihotis infection in cassava using a cDNA microarray. Plant Mol. Biol. 2005, 57, 393-410. [CrossRef] [PubMed]

25. An, D.; Yang, J.; Zhang, P. Transcriptome profiling of low temperature-treated cassava apical shoots showed dynamic responses of tropical plant to cold stress. BMC Genom. 2012, 13, 64. [CrossRef] [PubMed]

26. Yao, Y.; Geng, M.T.; Wu, X.H.; Sun, C.; Wang, Y.-L.; Chen, X.; Shang, L.; Lu, X.-H.; Li, Z.; Li, R.M. Identification, Expression, and Functional Analysis of the Fructokinase Gene Family in Cassava. Int. J. Mol. Sci. 2017, 18, 2398. [CrossRef] [PubMed]

27. Geng, M.T.; Yao, Y.; Wang, Y.L.; Wu, X.H.; Sun, C.; Li, R.M.; Fu, S.P.; Duan, R.J.; Liu, J.; Hu, X.W.; et al. Structure, Expression, and Functional Analysis of the Hexokinase Gene Family in Cassava. Int. J. Mol. Sci. 2017, 18, 1041. [CrossRef] [PubMed]

28. Wei, Y.; Shi, H.; Xia, Z.; Tie, W.; Ding, Z.; Yan, Y.; Wang, W.; Hu, W.; Li, K. Genome-wide identification and expression analysis of the WRKY gene family in cassava. Front. Plant Sci. 2016, 7, 25. [CrossRef] [PubMed]

29. Yan, Y.; Wang, L.; Ding, Z.; Tie, W.; Ding, X.; Zeng, C.; Wei, Y.; Zhao, H.; Peng, M.; Hu, W. Genome-wide identification and expression analysis of the mitogen-activated protein kinase gene family in cassava. Front. Plant Sci. 2016, 7, 1294. [CrossRef] [PubMed]

30. Wilson, M.C.; Mutka, A.M.; Hummel, A.W.; Berry, J.; Chauhan, R.D.; Vijayaraghavan, A.; Taylor, N.J.; Voytas, D.F.; Chitwood, D.H.; Bart, R.S. Gene expression atlas for the food security crop cassava. New Phytol. 2017, 213, 1632-1641. [CrossRef] [PubMed] 
31. Slewinski, T.L. Diverse functional roles of monosaccharide transporters and their homologs in vascular plants: A physiological perspective. Mol. Plant 2011, 4, 641-662. [CrossRef] [PubMed]

32. Hirai, T.; Heymann, J.A.; Shi, D.; Sarker, R.; Maloney, P.C.; Subramaniam, S. Three-dimensional structure of a bacterial oxalate transporter. Nat. Struct. Mol. Biol. 2002, 9, 597-600. [CrossRef] [PubMed]

33. Xu, G.; Guo, C.; Shan, H.; Kong, H. Divergence of duplicate genes in exon-intron structure. Proc. Natl. Acad. Sci. USA 2012, 109, 1187-1192. [CrossRef] [PubMed]

34. Scholz-Starke, J.; Büttner, M.; Sauer, N. AtSTP6, a new pollen-specific $\mathrm{H}^{+}$-monosaccharide symporter from Arabidopsis. Plant Physiol. 2003, 131, 70-77. [CrossRef] [PubMed]

35. Schofield, R.A.; Bi, Y.M.; Kant, S.; Rothstein, S.J. Over-expression of STP13, a hexose transporter, improves plant growth and nitrogen use in Arabidopsis thaliana seedlings. Plant Cell Environ. 2009, 32, 271-285. [CrossRef] [PubMed]

36. Schneidereit, A.; Scholz-Starke, J.; Sauer, N.; Büttner, M. AtSTP11, a pollen tube-specific monosaccharide transporter in Arabidopsis. Planta 2005, 221, 48-55. [CrossRef] [PubMed]

37. Bredeson, J.V.; Lyons, J.B.; Prochnik, S.E.; Wu, G.A.; Ha, C.M.; Edsinger-Gonzales, E.; Grimwood, J.; Schmutz, J.; Rabbi, I.Y.; Egesi, C. Sequencing wild and cultivated cassava and related species reveals extensive interspecific hybridization and genetic diversity. Nat. Biotechnol. 2016, 34, 562-570. [CrossRef] [PubMed]

38. Lynch, M.; Conery, J.S. The evolutionary fate and consequences of duplicate genes. Science. 2000, 290, 1151-1155. [CrossRef] [PubMed]

39. Moore, R.C.; Purugganan, M.D. The early stages of duplicate gene evolution. Proc. Natl. Acad. Sci. USA 2003, 100, 15682-15687. [CrossRef] [PubMed]

40. Williams, L.E.; Lemoine, R.; Sauer, N. Sugar transporters in higher plants-A diversity of roles and complex regulation. Trends Plant Sci. 2000, 5, 283-290. [CrossRef]

41. Gear, M.L.; McPhillips, M.L.; Patrick, J.W.; McCurdy, D.W. Hexose transporters of tomato: Molecular cloning, expression analysis and functional characterization. Plant Mol. Biol. 2000, 44, 687-697. [CrossRef] [PubMed]

42. Viola, R.; Roberts, A.G.; Haupt, S.; Gazzani, S.; Hancock, R.D.; Marmiroli, N.; Machray, G.C.; Oparka, K.J. Tuberization in potato involves a switch from apoplastic to symplastic phloem unloading. Plant Cell 2001, 13, 385-398. [CrossRef] [PubMed]

43. Yamada, K.; Kanai, M.; Osakabe, Y.; Ohiraki, H.; Shinozaki, K.; Yamaguchi-Shinozaki, K. Monosaccharide absorption activity of Arabidopsis roots depends on expression profiles of transporter genes under high salinity conditions. J. Biol. Chem. 2011, 286, 43577-43586. [CrossRef] [PubMed]

44. Liu, X.; Zhang, Y.; Yang, C.; Tian, Z.; Li, J. AtSWEET4, a hexose facilitator, mediates sugar transport to axial sinks and affects plant development. Sci. Rep. 2016, 6, 24563. [CrossRef] [PubMed]

45. Harrison, M.J. A sugar transporter from Medicago truncatula: Altered expression pattern in roots during vesicular-arbuscular (VA) mycorrhizal associations. Plant J. 1996, 9, 491-503. [CrossRef] [PubMed]

46. Finn, R.D.; Clements, J.; Eddy, S.R. HMMER web server: Interactive sequence similarity searching. Nucleic Acids Res. 2011, 39, W29-W37. [CrossRef] [PubMed]

47. Bailey, T.L.; Williams, N.; Misleh, C.; Li, W.W. MEME: Discovering and analyzing DNA and protein sequence motifs. Nucleic Acids Res. 2006, 34, W369-W373. [CrossRef] [PubMed]

48. Wang, Y.; Tang, H.; DeBarry, J.D.; Tan, X.; Li, J.; Wang, X.; Lee, T.-H.; Jin, H.; Marler, B.; Guo, H. MCScanX: A toolkit for detection and evolutionary analysis of gene synteny and collinearity. Nucleic Acids Res. 2012, 40, e49. [CrossRef] [PubMed]

49. Krzywinski, M.; Schein, J.; Birol, I.; Connors, J.; Gascoyne, R.; Horsman, D.; Jones, S.J.; Marra, M.A. Circos: An information aesthetic for comparative genomics. Genome Res. 2009, 19, 1639-1645. [CrossRef] [PubMed]

50. Trapnell, C.; Pachter, L.; Salzberg, S.L. TopHat: Discovering splice junctions with RNA-Seq. Bioinformatics 2009, 25, 1105-1111. [CrossRef] [PubMed]

51. Trapnell, C.; Roberts, A.; Goff, L.; Pertea, G.; Kim, D.; Kelley, D.R.; Pimentel, H.; Salzberg, S.L.; Rinn, J.L.; Pachter, L. Differential gene and transcript expression analysis of RNA-seq experiments with TopHat and Cufflinks. Nat. Protoc. 2012, 7, 562-578. [CrossRef] [PubMed]

52. Livak, K.J.; Schmittgen, T.D. Analysis of relative gene expression data using real-time quantitative PCR and the $2^{-\triangle \Delta C T}$ method. Methods 2001, 25, 402-408. [CrossRef] [PubMed] 
53. Wieczorke, R.; Krampe, S.; Weierstall, T.; Freidel, K.; Hollenberg, C.P.; Boles, E. Concurrent knock-out of at least 20 transporter genes is required to block uptake of hexoses in Saccharomyces cerevisiae. FEBS Lett. 1999, 464, 123-128. [CrossRef]

54. Morita, T.; Takegawa, K. A simple and efficient procedure for transformation of Schizosaccharomyces pombe. Yeast 2004, 21, 613-617. [CrossRef] [PubMed]

55. Chen, S.; Songkumarn, P.; Liu, J.; Wang, G.-L. A versatile zero background T-vector system for gene cloning and functional genomics. Plant Physiol. 2009, 150, 1111-1121. [CrossRef] [PubMed]

56. Wu, J.Z.; Liu, Q.; Geng, X.S.; Li, K.M.; Luo, L.J.; Liu, J.P. Highly efficient mesophyll protoplast isolation and PEG-mediated transient gene expression for rapid and large-scale gene characterization in cassava (Manihot esculenta Crantz). BMC Biotechnol. 2017, 17, 29. [CrossRef] [PubMed]

(C) 2018 by the authors. Licensee MDPI, Basel, Switzerland. This article is an open access article distributed under the terms and conditions of the Creative Commons Attribution (CC BY) license (http://creativecommons.org/licenses/by/4.0/). 